\title{
The 'Artificial Reason' of the Law
}

\author{
JEROME E. BICKENBACH Queen's University
}

In 1607, Chief Justice Sir Edward Coke related that he greatly offended James I when he insisted that the King should not be allowed to adjudge a legal case. Though it is true, Coke wrote, that "God had endowed His Majesty with excellent science, and great endowments of nature..." still "his Majesty was not learned in the laws of his realm of England, and causes which concern the life, or inheritance, or goods, or fortunes of his subjects, are not to be decided by natural reason but by the artificial reason and judgment of law, which law is an art which requires long study and experience, before that a man can attain to the cognisance of it."'

The point of this famous remark was to reinforce the constitutional principle that the administration of justice through law must be the prerogative of duly-appointed judges. Yet, though it undoubtedly made this point, the crux of Coke's argument, if one is moved to take it seriously, seems distinctly peculiar. Why, and in what sense, is the reason of law 'artificial'? And how is it that someone adept in natural reason, like the well-endowed King, could flounder in legal argumentation?

For a lawyer, especially a practicing lawyer, these questions pose no problem. In practice, legal argumentation is 'artificial', in the sense Coke obviously had in mind, simply because the law itself sets constraints on what is to count as an acceptable legal argument. These constraints take a variety of forms. Some go to the very heart of our system of law. Constraints imposed by the requirements of justice implicit in the doctrine of precedent and the rule of law are of this sort. As are statutory and constitutional provisions which constrain the choice of premisses of legal arguments and, not infrequently, channel the range of acceptable legal conclusions.

Moreover, in each area of the law fundamental legal principles directly shape the dialogic structure of a legal argument. The most obvious example of this is the criminal trial where the presumption of innocence creates a wide-ranging dialogic asymmetry which favours the accused and sets limits as to what will count as an acceptable prosecution. Indeed, the criminal law is replete with principles of procedure and rules of evidence that directly affect the procedural and substantive character of the inculpatory argument.

Finally, and perhaps most obviously, in every branch of the law, institutional and professional requirements, as well as general social, or public policy demands, dictate, to a degree that depends on the potential social impact of the case, which legal results are feasible and which are not.

For the practicing lawyer, these and countless other features of legal argumentation account for its 'artificiality' (and may also explain why legal judgment is an art requiring long study and experience). What Coke suggested James I lacked was knowledge of, and experience with, substantive law as well as the various contexts in which legal reason operates. The King wished to intrude into the arena of the law, to come in from outside (and down from above) in order to impose a decision on the court. To this Coke rightly responds that, though the King may have the power to do this, he lacks the authority. For this is not what it means to reach a judicial 
decision, pursuant to the artificial reasoning of the law.

Is there anything in this that should be of interest to the informal logician? There is indeed. Legal argumentation is practical, normative, institutional and substantively constrained reasoning, and as such it may be the best example we have of fully contextualized, practical argumentation. The logical force of a legal argument-its point, its function, and in some respects, its very meaning - can only be properly appreciated as it is used, from within the discourse of the law. Legal argument is situated reasoning and cannot, without distortion, be abstracted from its various, actual settings, nor severed from its various, actual functions.

To say that legal argumentation is fully contextualized is to make a claim about its character as a rational process. This is different from assessing the logical form of a particular collection of propositions arranged in the shape of an argument. The 'artificality' of legal argumentation, as Coke saw, is not a matter of the form of reasoning used, or whether specialized and nonstandard rules of inference link premisses and conclusion. It is principally a matter of the perspective, or locus of the reasoner, including the expectations, presumptions and duties of the social, and professional, roles that reasoner occupies.

Being engaged in the process of legal argumentation, in other words, means precisely not being an abstract reasoner, concerned exclusively with the formal structure of a set of propositions, some identified as premisses, others as conclusions. Legal argumentation is a dynamic process, it is exploratory, creative, and interpretive. The lawyer, judge, or legal scholar is not presented with static premisses from which he or she must draw conclusions by instantiating inference rules; the job is almost entirely that of finding, and then making sense of the premisses within a given legal context. The locus of the formal logician is inappropriate to legal argumentation because such reasoning is thoroughly embedded in a complex social practice, and to engage in it is, minimally, to be versed in legal content, obedient to the aims of the practice, and conscious of the diverse functions legal argumentations performs in different settings.

For example, in the juridical setting, since legal argumentation is practical and normative, its function is to explain and justify the judge's decision to characterize a concrete situation in terms of a series of legal concepts and norms. Further, since legal argumentation is institutional and substantively constrained, its function here is to advance the development of the law in a manner that accords with the social and political character of the legal system. In the setting of advocacy, on the other hand, the lawyer arguing before the court must rely on, by engaging in, the rhetorical function of rational persuasion: he or she must 'make a case'. And finally, in the setting of legal scholarship, legal argumentation serves as the only legitimate vehicle for criticising legal judgments and motivating suggestions for legal change.

But legal argumentation should be of interest to the informal logician not merely because it offers such a rich field of examples of situated argumentation. It may also be a superb test case for the thesis that the apparatus of formal logic, be it deductive or inductive, does not adequately capture the logical character of argumentation-at least when argumentation is understood as the practice of rational communication, rather than as a set of abstracted, or nonsituated, statements ordered by relations of implication. It may even turn out that a philosophically acceptable account of legal argumentation will shed light on the logical character of contextualized rationality in general.

Now, it has long been thought that there is something philosophically interesting about legal argumentation. It is not a computational process, nor does it appear to involve inductive generalizations, at least of 
the familiar sort. It has, though, been a matter of some dispute what accounts for its special character. More than forty years ago, in an article entitled "Gods"', John Wisdom suggested that legal argumentation may be a paradigm instance of a variety of reasoning which is, among other things, integral to philosophical inquiry. In courts of law, he wrote, it sometimes happens that there is agreement as to the facts, but disagreement about what these facts mean.

In such cases,

... we notice that the process of argument is not a chain of demonstrative reasoning. It is a presenting and representing of those features of the case which severally cooperate in favor of the conclusion, in favor of saying what the reasoning said, in favor of calling the situation by the name by which he wishes to call it. The reasons are like the legs of a chair, not the links of a chain.

The procedure here resembles that of scientific discovery, Wisdom thought, not because it is inductive in form, but because it is "horizontally extensive-it is a matter of the cumulative effect of several independent premises, not of the repeated transformation of one or two." The logic of the legal dispute, in short,

..has its own sort of logic and its own sort of end-the solution of the question at issue is a decision, a ruling by the judge. But it is not an arbitrary decision though the rational connections are neither quite like those in vertical deductions nor like those in inductions in which from many signs we guess at what is to come; and though the decision manifests itself in the application of a name it is no more merely the application of a name than is the pinning on of a medal merely the pinning on of a bit of metal.

These days, Wisdom's images and metaphors are thought to be suggestive but far too imprecise to stand up to scrutiny. And unfortunately-although it is not at all clear that this was his intention-he left the distinct impression that he was trying to identify in the 'case-by-case' reasoning of the law an alternative, formal logic, a competitor to deduction and induction. So it is that some writers insist that he misunderstood the nature of deduction, and others that he misunderstood induction. ${ }^{3}$

For their part, lawyers and jurisprudes have only relatively recently paused to consider what makes legal argumentation special. Understandably, jurisprudential discussions have always been more sensitive to the variety of argumentative styles and contexts, and less concerned to abstract or systematize legal reasoning. Wesley Newcomb Hohfeld's hyper-rigorous analysis of the notion of a legal right, ${ }^{4}$ though popular with philosophers, has always been something of a curiosity among lawyers, principally because of its high level of abstraction.

Although the authors of recent jurisprudential accounts have moved off in many different directions, most have been strongly influenced by the classic discussions of Benjamin Cardozo, ${ }^{5}$ Edward Levi, ${ }^{6}$ Jerome Frank, ${ }^{7}$ and, to a lesser degree, the Australian Julius Stone, ${ }^{8}$ all of whom, in one way or another, have tried to construct a picture of legal argumentation which a practicising lawyer would recognize. Because of this sensitivity to the 'artificality' of legal argumentation, this picture may appear extraordinarily messing, ad hoc, and even incoherent to the analytically-minded philosopher. In the lawyers" hands, legal argumentation looks far more like a kind of politicized literary criticism than it does reasoning.

A characteristic feature of recent scholarship on legal argumentation, especially in the last decade or so, is a clear division of opinion between, for lack of better terms, the optimists and the pessimists. The optimists believe that legal argumentation is fundamentally rational and can, if used properly in the best conditions, yield clear and correct legal judgments. Though aware of the possibility of indeterminacy in legal interpretation, these scholars believe that, almost in spite of the countless political and social forces that shape it, legal 
argumentation can solve legal problems in a rational fashion. The most famous optimist is Ronald Dworkin who has seen in the political component of the context of legal argumentation the grounds for believing that legal argumentation can yield 'right answers', at least when employed by Herculean judges under ideal conditions. ${ }^{9}$

As one might expect, the pessimists deny all this. Following in the tradition of the American Realists, the current Critical Studies Movement has produced scores of pessimists. Indeed, the thesis that legal argumentation is, at best indeterminate and irrational, and at worse a subtrafuge for ideological manipulation, is a central plank in their platform. These writers, and they seem to be dominating the literature these days, have left behind the usual tool of philosophical analysis in favour of more exotic approaches, such as Derridian deconstruction. Significantly, though, for the pessimists, it is precisely because legal argumentation is contextualized that it is subjective, indeterminate, and irrational. The pessimists argue that the context of legal argumentation is characteristically dominated by a judge who will, inevitably in their view, use his or her moral values and political ideology as the basis for the legal argument, all the while disguising this subjectivity with technical language and other flummery of the law.

Though the law journals are filled with debates between the optimists and the pessimists, philosophers in the analytic tradition have not been moved to enter this dispute, at least in these terms. Instead, these writers find legal argumentation philosophically interesting, even intriguing, but for a very different reason. It appears that the 'artificality' of legal argumentation poses a challenge to the projects of rational reconstruction and moral reform. This challenge only arises in the context of an approach to legal argumentation that can be characterized by four groundrules or assumptions. ${ }^{10}$

The first of these is the assumption that, whether apparent or not in practice, deductive reasoning is the salient feature of legal argumentation. Although reasoning in the law relies on rhetorical techniques and makes extensive use of argument from analogy and the odd inductive argument, at the end of the day, when the judge's reasoning is analyzed and assessed, deductive validity is the only appropriate standard. This being so, though a philosophical theory of legal argumentation should strive to account for the diversity of legal premisses, constraints, argument forms, and other products of contextualization, all of this has no effect on the logical character of legal argumentation as such, since that is simply a matter of the instantiation of deductive rules of inference. (Call this the assumption of Deductivism.)

A second ground rule is that the theorist must be aware of and careful to distinguish between the psychological and the logical dimension of legal reasoning-between, that is, the context of discovery and the context of justification. For, however interesting it may be to disclose the process by which a judge makes his or her way through the submissions and arrives at a reasoned judgment, what is of philosophical significance is the product, rather than the process of legal argumentation. We get to the heart of the matter when we strip away from legal argumentation all that is merely a matter of social practice, distil the premisses and conclusions, thereby disclosing the legal justification.

Thirdly, although it is the practice in a court of law to set out legal reasons with the expressed purpose in mind of rationally persuading the judge, the logical value of these reasons is not a function of their capacity to persuade, but to logically justify. Thus, the justificatory function of legal argumentation takes precedence over its other functions, and is indeed the only function of philosophical interest.

Finally, for those philosophers whose concern is not merely to logically reconstruct legal argumentation but to assess 
it as a political institution, it is assumed that the critic must suggest ways of reforming the institution in order to further specific moral or political aims. Richard Wasserstrom, to take a prominent example of this approach, has put forward a reformed version of legal reasoning which would effectively abandon the doctrine of precedent, and seriously compromise the rule of law, in order to implement a thoroughgoing utilitarianism. ${ }^{11}$ For these writers, the analysis of legal contexts and settings, and the formal description of characteristic patterns of reasoning, are but preliminary steps to a thoroughgoing, moral reconstruction of legal argumentation. (Call this the assumption of Moral Reconstruction.)

Taken together, these systematic assumptions suggest that an adequate account of legal argumentation will consist of a series of rules, analytic techniques, and other devices for isolating the end-product of the process of legal argumentationnamely a justificatory legal argument the conclusion of which is a statement of law. Once this argument is isolated, other rules will reconstruct the background deductive inference which, ex hypothesi, captures its formal, logical essence. The overall rationality of the process of legal argumentation depends in the first instance on the formal validity of the legal argument that is produced, and secondly, on the moral acceptability of the premisses relied on.

Now, on this approach, 'artificiality' is a challenge to rational reconstruction, a challenge created by the fact that legal argumentation involves a specialized subject-matter and takes place in an institutional setting in which specific constraints are presumed and important premisses are left out. Thus, the job of the logical reconstructor will invariably involve making explicit the legal enthymeme.

More than a few of those who are engaged in this philosophical enterprise leave one with the impression that they can find nothing particularly special about the reasoning involved in legal argumentation.
The view seems to be that what distinguishes it from other instances of deductive reasoning is simply an issue of granularity - the detail supplied by the context in which this form of deductive reasoning takes place. One may even get the impression that they agree with the Critical Legal scholars that all of the contextual background to legal argumentation is so much window-dressing that can, and should, be detached from the argument itself, so that the logical essence of legal reasoning is revealed, and moral reform can begin.

There is, though, a hint of fraud in this last attitude. For the philosopher who is convinced that legal argumentation is nothing more than applied deduction can all too easily make this case. It is not much of a challenge, though sometimes it is an interesting exercise, to reformulate a complex, discursive argument-such as one might find in a judge's written reasons in a legal action-in order to generate a series of simplistic deductive inferences. One merely selects from the background contextual material what one needs to supply the missing terms and premisses, puts it into some sort of symbolism, and there it is, modus ponens. This is supposed to show that legal argumentation is deductive in form.

Mainstream jurisprudential writers have always rejected this over-simplified and over-formalized picture of legal argumentation. But, increasingly, so too have philosophers, even those who are committed to the four groundrules set out above. We are beginning to see a different attitude toward the "artificality" of legal argumentation, and a deeper respect for the character of legal practice.

Certainly the best example of this change in tone can be found in the recently translated work of the German scholar, Robert Alexy, entitled A Theory of Legal Argumentation. ${ }^{12}$ Alexy masterfully blends together analytic metaethical theory, Jurgen Habermas " consensus theory of truth, topic theory, amd Chaim Perelman's theory of argumentation to produce a complex and 
sophisticated account of legal argumentation. His starting point is the view that legal argumentation is a special case of practical reasoning because it is contextualized, and that intrinsically legal constraints on argumentation must be factored into the processes of legal justification. Though the correctness of legal argumentation is a matter of deductive validity, it is also subject to specific, legal constraints that capture, in explicit form, the effects of contextualization on legal reason.

Like Neil MacCormick, whose 1978 book Legal Reasoning and Legal Theory ${ }^{13}$ initiated this approach, Alexy sets out to devise an account of legal argumentation that is relevant to actual legal practice, yet both logically and morally sound. Though the only appropriate standard of logical correctness is deductive validity, still it can not be seriously maintained that the application of law involves no more than a logical subsumption under abstractly formulated major premisses. The question, then, is how can the 'artificiality' of legal argumentation be taken seriously in light of the demands of deductive form.

Alexy's solution relies on a distinction between internal and external legal justification. Internal justification is the process by which a judge seeks to justify the actual judgment he or she has reached in a particular case. Legal norms of one sort or another form essential, major premisses in this argument. Yet, in order to justify these premisses rationally, we must turn to external justification where extra-legal standards are applied.

Generally, internal justification takes the following form:
(1) $(\mathrm{x})(\mathrm{Tx} \rightarrow \mathrm{ORx})$
(2) $\mathrm{Ta}$
(3) $\mathrm{ORa}$

Where the variable ranges over juristic persons; the complex predicate $T$ describes the operative facts of the legal norm that is expressed by the first premiss; and $R$ expresses what the juristic subject of the norm is obliged to do.

Yet, Alexy is quick to add, though this is the form of internal justification, it would be extraordinary in the extreme to find instances of either of the two premisses in practice. The bald statement of the norm represented by premiss (1) may only be implicit in a complex collection of rules and principles. There may be several alternative statements of the operative conditions of the norm's application; or it may be silent on what conditions must exist before it applies. The general legal norm may require supplementing with other legal norms; or there may be several possible legal consequences of the same norm; or the language of the norm may be so general as to require preliminary specification before it can be intelligibly, and consistently applied. And so on.

So Alexy is aware that for this legal syllogism to represent actual legal practice it must be augmented with other, subsidiary premisses. These supplementary premisses will undoubtedly involve other legal norms, which must in turn be justified by the process of internal justification. What was originally a straightforward deontic syllogism will, invariably, turn into a complex and lengthly argument. Yet, however complex, the argument will never lose is deductive form.

Internal justification is legal argumentation as its exists in practice. But, Alexy insists, each of the legal norms involved in internal justification is subject to external justification. The formal character of this meta-level justification is governed by two axioms of practical reasonablenessnamely, that there be at least one universal norm per syllogism, and that the conclusion of the syllogism must follow deductively from the premisses. ${ }^{14}$ Yet, at the same time, the content of external justification must reflect aspects of the context of legal argumentation at the level of practice.

Thus, for example, rules of positive law, which are institutionally validated, will help to set the boundaries of external justifica- 
tion. For similar reasons, the rules associated with the doctrine of precedent and the hierarchy of the courts, rules governing the acceptability of factual evidence, and the canons of statutory interpretation are all input into arguments of external justification. Thus, the law itself provides, in the form of legal norms, many of the major premisses of external justification.

Still, since external justification is extralegal, these legal norms may be in competition with other norms, logical and moral. The requirements of practical reasonableness, such as universalizability and consistency will form major premisses in external justifications, as will certain general, moral imperatives. In particular, the moral foundation of legal argumentation, Alexy believes, is provided by the Habermasian account of the conditions of the ideal speech situation.

Though it is difficult in a short space to do justice to Alexy's theory, it is enough to say that he strives to take the contextualized character of legal argumentation seriously in a general account that is firmly rooted in the groundrules of Deductivism and Moral Reconstruction. There is, though, no doubt that contextualization, for Alexy, remains solely a matter of the content of the premisses of legal syllogisms. Deductive form dictates the process of legal argumentation and Alexy assumes, as anyone working with the four groundrules must, that there is no logical difference between participating in the process of legal argumentation and logically assessing the end-result of that process.

This means that Alexy never wavers from the view that to be engaged in legal argumentation is to proceed as if one were setting out the building blocks of a deductive argument: form dictates content, so to speak. The locus of the legal reasoner is not that of someone confronting a legal problem, as yet unsolved, but that of an abstracted, logical overseer who has access to special information. This logical overseer surveys a collection of propositions, selects some and extracts others from the legal background, arranges them as premisses, and draws deductive inferences. Thus legal argumentation, for all its 'artificality' remains for Alexy, to return to John Wisdom's images, like the links of a chain rather then the legs of a chair.

Is there another approach the informal logician might pursue in order to make sense of legal argumentation as contextualized rationality, in particular one which views the process of argumentation from the forward-looking perspective of the problemsolver, rather than the backward-looking perspective of the logical overseer? Are there philosophically respectable alternatives to the four groundrules that have characterized most philosophical treatments of legal argumentation?

Increasingly, those concerned to do justice to legal argumentation have turned to the literature on philosophical hermeneutics, especially as developed by Hans-Georg Gadamer in his classic text, Truth and Method. ${ }^{15}$ Applied to legal argumentation, the hermeneutical approach holds out the prospect of showing why 'artificality' is not only a significant and essential feature of legal argumentation, but is also a characteristic aspect of contextualized rationality. The central tenet of such an approach is that the principal and characteristic activity of the participant in legal argumentation is not that of drawing inferences but of comprehending and making sense of a text in light of a concrete problem of application. Legal argumentation is not inferential but interpretative.

The governing principle of philosophical hermeneutics, on Gadamer's view, is that in any endeavour where understanding is the aim there is an essential, and meaningful, interaction between the interpreter and the object of interpretation. This means that interpretation is contextualized in two dimensions. The text, or other object of interpretation, is situated within a discourse and set of social practices which provide its context. Moreover, the interpreter is also 
contextualized, by the terms of the discourse and social practices, by the background beliefs and values through which the interpreter views the text, and by the obligations that attach to one whose interpretation will warrant a particular judgment.

Part of what it means to say that legal argumentation is contextualized or "artificial' is that it is situated in specific contexts and so has identifiable functions and practical ends. Legal argumentation is essentially involved in the application, in concrete instances, of general legal norms. But this is also a salient feature of interpretation, as understood in the hermeneutic tradition. Gadamer argues that a judge can be distinguished from a legal historian precisely in this regard: from the perspective of the judge the law cannot be understood aesthetically, historically, or in any other abstracted fashion. The law has a claim on what is present and concrete, a claim to be applied in particular cases.

But the application of the law is reciprocal. While the judge must apply his or her best understanding of the law to the case at hand, he or she must also apply the law to that understanding, inasmuch as the law is authoritative and decisions must be made with reference to the law, not to a particular judge's understanding of it. In this sense, moral reform, and other forms of extra-legal critique, are irrelevant to legal argumentation.

But even if all this is true, why should this mean that the background, working logic of legal argumentation is something other than deduction? Can we not understand legal interpretation to be no more than a matter of selecting which of many possible readings of a general, legal norm is both consistent with the surrounding field of related legal norms and in accordance with institutional and policy requirements, as in fact Alexy suggests? Does the hermeneutic emphasis on interpretation and application really demand the replacement of deduction with some other model or form of reasoning?
It does, but not because, once completed, a legal argument can violate the most basic rules of deductive inference with impunity. It is not a question of substituting a new form of inferential reasoning for deduction, but of turning to a very different, but equally rational, process of argumentation, namely interpretation. On the deductivist model, interpretation is at best a process of choosing one reading over another. Once chosen, a syllogism can be created; but the process of choosing can not itself be a mode of argumentation since it is neither inferential nor justificatory. But this is precisely what the legal hermeneutician denies: legal hermeneutics is not only dynamic, interactive, and productive of meaning, it is also rational and justificatory without being inferential.

In the context of legal argumentation, that is, the logical relationship between general, legal norms and legal decisions is not a matter of the subsumption of the particular to the general since, in interpretation, the general and the particular supplement and complement each other. Indeed, just because it is general the general legal norm has no determinate meaning prior to application (or as Gadamer puts this point: understanding is always understanding in application). Thus, the application of a general norm inevitably alters the meaning of the norm.

Thus any version of the legal syllogism, however complex, will fail to capture the essential, interpretive logic of the process of legal argumentation. Deductive reasoning, for all its power, remains an essentially computational template for assessing the truth-preserving character of relations between propositions, whose meaning and significance is fixed and given. In deduction, one can not debate the meaning of a term as one assesses the deductive validity of the argument whose propositions contain that term. Deduction proceeds only when interpretation is completed; that is why deductive validity is an inapposite model for legal argumentation. 
By contrast, in the interpretative model offered by the hermeneutic tradition, premisses and conclusions interact, the meaning of a general norm arises from the meaning of that norm in application, and the meaning of the application is a function of the meaning of the general norm. Of course, when decisions have been madethe court has ruled-and concepts once open to interpretation have, as lawyers say, 'crystalized', and we are told what is and what is not an instance of a legal norm, then the rules of deductive inference can be applied. But, once again, to test for deductive validity is not to engage in legal argumentation, since the test is only appropriate when the argumentation is over.

Now, whatever may be said of this hermeneutical thesis from a logical point of view, from the point of view of legal practice it is obviously correct, at least for those cases where the legal issues are contentious. It is simply false that when advocates set out their legal submissions at trial, or when judges make their why through the submissions to arrive at a decision, or when legal scholars criticise the decision, that considerations of deductive validity play any role whatsoever in the process. But, again, this is not because legal argumentation is an instance of a non-deductive form of reasoning, or because it is deductively invalid. Deductive validity is an inappropriate model of legal argumentation because it simply cannot do justice to what actually takes place in legal argumentation.

To take a trivial example, section 8 of the Canadian Charter of Rights and Freedoms purports to protect individual citizens against "unreasonable searches and seizures". From the moment this general legal norm was constitutionally enacted its meaning was dependent upon the interpretation of "illegal searches" found in the preCharter caselaw. That is, the general norm protecting citizens against unreasonable searches had no determinate meaning outside of that captured by the particular applications of a prior norm. As each section 8 case is litigated before the Supreme Court of Canada, and as each judgment is rendered, the meaning and significance of that general norm will be altered, perhaps radically.

Thus, Gadamer is correct when he says that, with each application of a legal norm, the judge in effect determines the law, not merely what it was, but what it is and will be. The judge revises the law, not by means of 'judicial legislation'-an oxymoron which signifies the illegal creation of new law-but by understanding the law already in force. Acquiring legal understanding though concrete application is an interpretive processs internal to the law, and the principal function of legal argumentation.

If deductive validity is not the appropriate model for legal argumentation, so understood, what is? Gadamer himself seeks guidance from Aristotle's notion of practical wisdom, or phronesis. Practical judgment, for Aristotle, is a matter of resolving concrete normative questions about what ought to be done through an exploration of the meaning and significance of general, normative principles. Since no general normative principle could anticipate every possible instance of the kind of practical problem it involves, practical wisdom is a matter of setting out real and imagined instances and comparing them to the general principle, weighing each against the other, in light of the actual features of the problem one is attempting to solve.

In the same way, hermeneutical interpretation seeks the concrete application of general rules or principles through an exploration of the meaning of those rules or principles as illuminated in particular cases, real or imagined. Where there is a tradition of prior applications of a rule or principle-as there usually is in law-that tradition necessarily forms the basis for interpretation. Yet this body of previous judgments about the application of a norm will rarely uniquely determine how the present case should be decided. The interpreter must seek other ways of understanding the 
present case, as these are illuminated by other cases. At no point in this process, Gadamer insists, will the interpreter accumulated conclusive proof that one interpretation is better than another; the aim is rather to bring together the cumulative effect of many inconclusive reasons for an interpretation, in order to produce a legally relevant justification of a legal judgment.

Perhaps this is what John Wisdom had in mind when he spoke of a process of argument that is not a chain of demonstrative reasoning but rather a "presenting and representing of those features of the case which severally cooperate in favour of the conclusion." Of course, much more would have to be said to convince the informal logician that hermeneutical interpretation or Aristotlean phronesis are adequate models for legal argumentation in particular, and contextualized reasoning in general. Yet, it may well be that the 'artificality' of legal argumentation will only manifest itself in terms of those models. ${ }^{16}$

\section{Notes}

1 Prohibitions del Roy (1607) 12 Co, Rep. 63.

2 John Wisdom, "Gods" (1944-45) Proceedings of the Aristotelian Society, 189, 193-195.

3 See the brief discussions of Wisdom's characterization of legal reasoning in Joseph Horovitz, Law and Logic (New York, SpringerVerlag, 1972), Ilmar Tammelo, Modern Logic in the Service of Law (New York, SpringerVerlag, 1978) Richard Wasserstrom, The Judicial Decision (Stanford, Stanford University Press, 1961), and Martin P. Golding, Legal Reasoning (New York, Knopf, 1984).

4 Fundamental Legal Conceptions (New Haven, Yale University Press, 1919).

5 The Nature of the Judicial Process (New Haven, Yale University Press, 1921).

6 An Introduction to Legal Reasoning (Chicago, University of Chicago Press, 1949).

7 Law and the Modern Mind (New York, Tudor Publishing, 1936) and cf. Karl Llewellyn, The Bramble Bush (Dobbs Ferry, New York, Ocena Publishing, 1930).

8 Legal System and Lawyer's Reasoning (London, Stevens and Sons, 1964).

9 See "Model of Rules-I" and "Hard Cases" in Taking Rights Seriously (Cambridge, Harvard University Press, 1978).
10 The first three of these assumptions are versions of those discussed by Golding in Legal Reasoning, Chapter 1.

11 The Judicial Decision (1961).

12 A Theory of Legal Argumentation: The Theory of Rational Discourse as Theory of Legal Justification, translated by Ruth Adler and Neil MacCormick (Oxford, Clarendon, 1989).

13 Neil MacCormick, Legal Reasoning and Legal Theory (Oxford, Clarendon Press, 1978).

14 Theory of Legal Argumentation, 221-230.

15 Hans-Georg Gadamer, Truth and Method (New York, Seabury Press, 1975); I am relying in part here on the discussion of legal hermeneutics by Joel C. Weinsheimer in Gadamer's Hermeneutics: A Reading of Truth and Method (New Haven, Yale University Press, 1985), 185-195.

16 An earlier version of this paper was presented, in June, 1989, in Windsor Ontario, at the Third International Symposium on Informal Logic. I wish to thank an unnamed referee of this paper for remarks which prodded me to make myself clearer.

JEROME E. BICKENBACH DEPARTMENT OF PHILOSOPHY QUEEN'S UNIVERSITY KINGSTON, ONTARIO K7L 3N6 